\title{
Dinámicas de participación en la formación de lugares-patrimonio: humedales y centro histórico en Bogotá
}

Dolly Cristina Palacio T. | Facultad de Ciencias Sociales y Humanas, Universidad Externado de Colombia

URL de la contribución <www.iaph.es/revistaph/index.php/revistaph/article/view/3452>

\section{RESUMEN}

Este artículo presenta los resultados de 10 años de investigación, entre 2001-2011, sobre las dinámicas de participación en la gestión del patrimonio natural y cultural en Bogotá (Colombia).

Se presentan el caso de los humedales y el del centro histórico, mostrando las diferencias en lo que interesa a los procesos participativos. Se definen ambos desde la noción de lugar-patrimonio, evidenciando las formas de interacción social, socioespacial y sociombiental que moldean el paisaje del cada lugar.

Se evidencia la alta participación ciudadana de los habitantes vecinos de los humedales en su gestión y la dificultad de involucrar a los habitantes del centro histórico. Cada uno de estos patrimonios ha sido construido por una heterogeneidad de actores en procesos sociales distintos.

Aplicando algunas herramientas analíticas del análisis de redes sociales (ARS), se describen las topologías que adquieren estas relaciones para cada caso y se muestra la influencia de los actores en la gestión del patrimonio. Esta perspectiva relacional permite evidenciar las formas de interacción, pero también puede dar luces para la construcción de procesos donde el diálogo entre estos actores genere nuevos escenarios de participación.

\section{Palabras claves}

Bogotá (Colombia) | Gestión | Gestión ambiental | Humedales | Participación social | Patrimonio cultural | Patrimonio natural | Planificación | Redes sociales | 


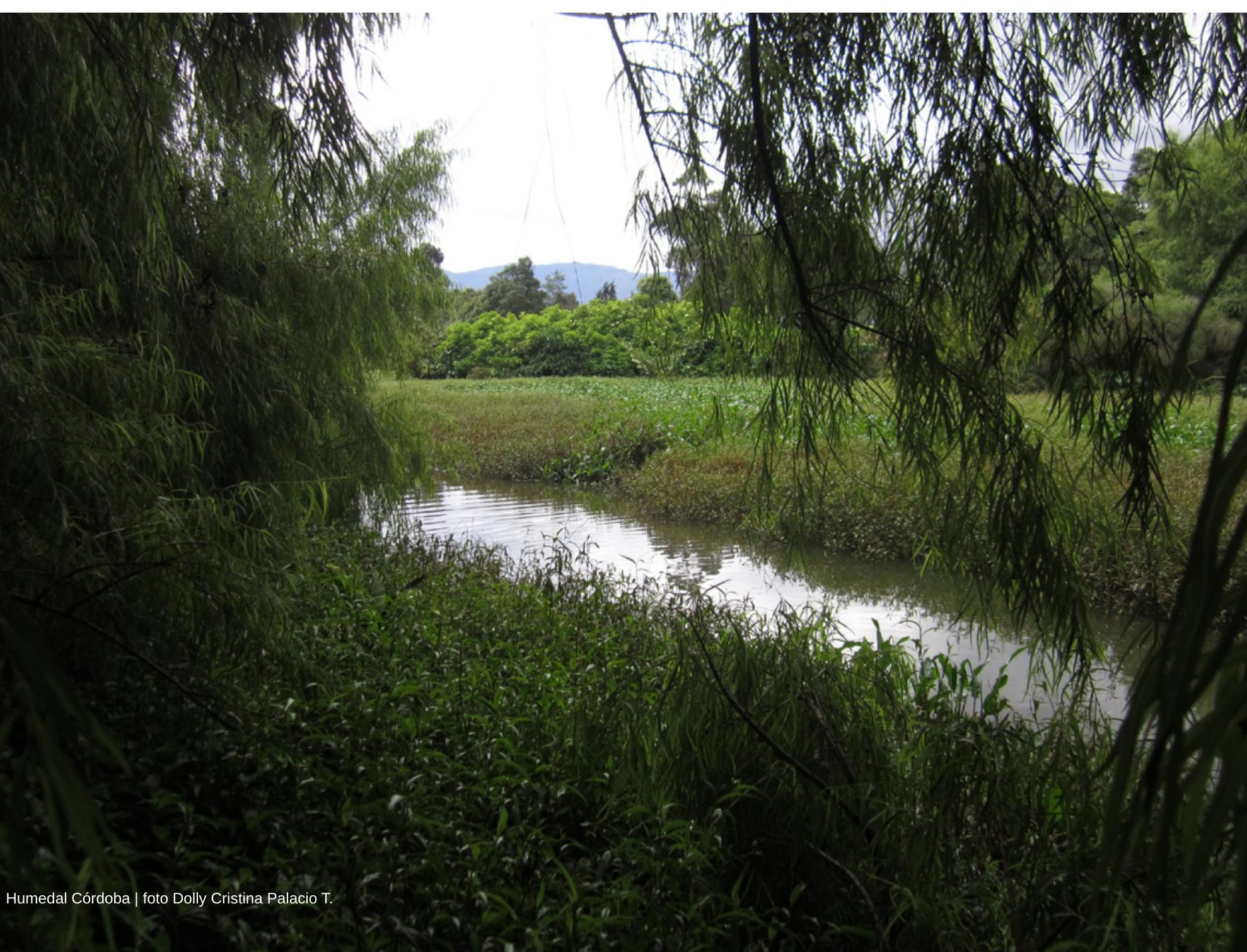




\section{INTRODUCCIÓN}

1

El grupo Procesos Sociales, Territorios y Medio Ambiente, de la Universidad Externado de Colombia, realiza tres investigaciones sobre humedales y el centro histórico, todas financiadas por Colciencias en 2001, 2004 y 2009, respectivamente.

\section{2}

La heterogeneidad expresa la diferencia marcada por la naturaleza de los actores definidos como actantes en la práctica. Es decir hay heterogeneidad cuando hablamos de la marcada diferencia en la naturaleza de los actantes entre humanos diferenciados por género, de grupos étnicos y culturales, grupos de interés, grupos con orientaciones políticas distintas y no-humanos: objetos y otros seres vivos y elementos del entorno como construcciones, materiales, animales y plantas, el agua entre otros (LAW, 1992).

3

Callon define la "traducción" como el proceso mediante el cual los actores problematizan, interesan, enrolan y movilizan a otros actores y elementos del entorno para logar sus propósitos (CALLON, 1986).
Los humedales y el centro histórico de Bogotá se han definido como lugares-patrimonio a partir de los resultados de un conjunto de investigaciones realizadas entre 2001 y $2011^{1}$. El lugar-patrimonio es una noción que permite comprender el patrimonio como resultado de un tejido social dinámico que con su acción determina la valoración de los lugares (HAMMEN; LULLE; PALACIO, 2009). Dicho tejido se produce a partir de la interacción entre un conjunto amplio de actores heterogeneos ${ }^{2}$ y sus distintas traducciones ${ }^{3}$ del lugar. En consecuencia, como tal, los lugares-patrimonio emergen como una síntesis socioespacial y socioambiental situada, dinámica y en tensión entre actores que usan, se apropian y valoran el lugar de distintas maneras (PARIAS; PALACIO, 2006). Por lo tanto, los bienes patrimoniales no son objetos separados de las dinámicas sociales que los producen, sino que son en tanto éstas últimas se asocian al lugar, moldeando su paisaje y definiendo su valor. En consecuencia, la polivalencia que se genera de estas dinámicas que producen el patrimonio, entre otras, revela dificultades para articular los procesos de gestión y planeación propios de los gobiernos locales y muestra el gran potencial para el desarrollo de acciones en el marco de la planeación y la gestión participativa del mismo.

En este artículo se exponen algunos resultados que contrastan los procesos de planeación y gestión del patrimonio para los dos casos dentro de la ciudad: los humedales y el centro histórico. Se evidencian diferencias en cuanto a los procesos de apropiación social del patrimonio natural y cultural; se pone de manifiesto que el patrimonio relacionado con el centro histórico está anclado en los discursos de los grupos hegemónicos de la ciudad, interesados en promover proyectos de consolidación de una identidad nacional abstracta, que muchas veces está alejada de los intereses de sus habitantes en su calidad de ciudadanos y sus organizaciones. La defensa y la gestión ambiental de los humedales, por el contrario, son una expresión sentida de sus vecinos como habitantes y ciudadanos que se organizan para rescatar un valor ecológico para la ciudad y que se vuelve para muchos un proyecto de vida y una propuesta de modelo de ciudad alternativo que difiere del modelo clásico de ciudad compacta y separada de lo rural y de lo natural.

La historia de los humedales de la sabana de Bogotá es muy antigua y dinámica. Si bien estos lugares han sufrido cambios producto de las dinámicas geológicas, climáticas, biológica y culturales en los 3 millones de años que tienen de existencia, ellos no experimentan transformaciones tan fuertes como las acaecidas en los últimos 60 años. Los humedales de Bogotá en el presente son relictos de los pantanos que formaban alrededor de doscientos ríos y quebradas que bajaban de los cerros orientales hacia la cuenca alta el río Bogotá que nace en la zona media de la cordillera oriental de Colombia. Esta gran sabana cuya extensión es de $1.413 \mathrm{~km}^{2}$, alberga una ciudad de 


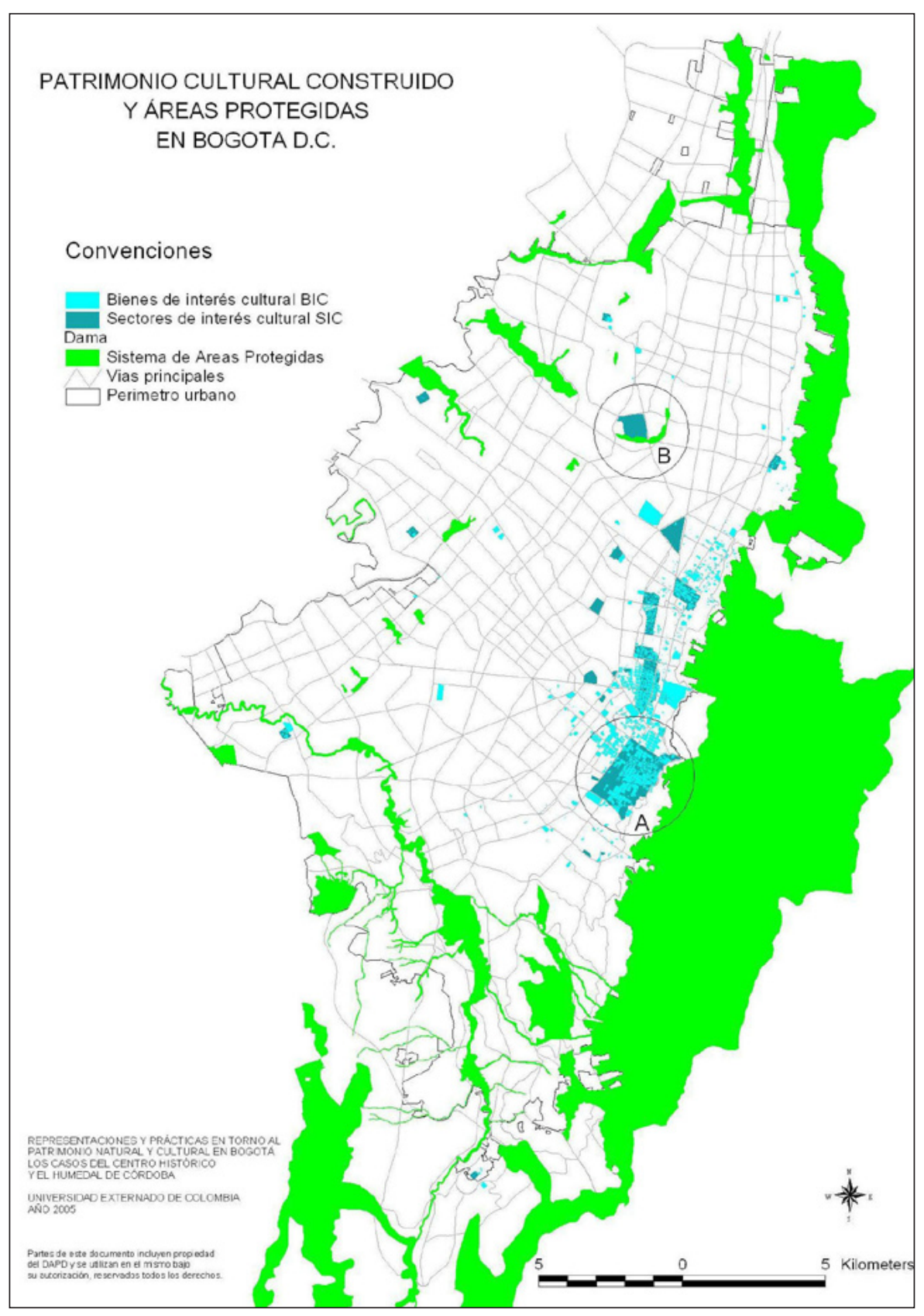

Mapa del patrimonio cultural construido y las áreas protegidas en Bogotá. En círculos: A, el centro histórico y B, el humedal Córdoba y la zona urbana circundante ambas declaradas BIC | fuente CHAPARRO, 2006

casi 8 millones de habitantes y ocupa $350 \mathrm{~km}^{2}$ de la gran sabana altoandina. Estos relictos son 16, con una extensión total de aproximadamente 800 ha. Están localizados precisamente en el límite occidental de la ciudad y han sido declarados parques ecológicos distritales en el Decreto 619/2000, por el cual se adopta el Plan de Ordenamiento Territorial de Bogotá. 


\section{4}

Decreto 264 de 1963 que declara el centro histórico de Bogotá, monumento nacional y las disposiciones del decreto 678 de 1994 y la ley 397 de 1997 que establece que "los bienes declarados monumentos nacionales con anterioridad a la presente ley, así como los bienes integrantes del patrimonio arqueológico serán considerados como bienes de interés cultural".

\section{5}

Documento 3162 del Consejo de Política Económica y Social (CONPES).

6

Distrito Capital es una figura territorial única en Colombia para denominar la ciudad capita y las localidades tanto urbanas como rurales. Es una entidad territorial de primer orden a mismo nivel de los departamentos. Las 20 localidades en las que se divide este territorio incorporan zonas urbanas que antes eran municipios independientes y que hoy son localidades conurbadas con la ciudad origina y su territorio circundante que incorpora un área rural (Constitución Política de Colombia, 1991).

7

Plan de Ordenamiento Territorial (POT) 2000 y ratificados en la reforma del POT en 2013
El centro histórico de Bogotá está ubicado en la localidad de La Candelaria, que comprende la ciudad fundacional y centro colonial español erigido en 1538 y las áreas urbanas que se desarrollaron en su etapa republicana, entre finales del siglo XIX y principios de XX. Está conformado por los barrios de Belén, las Aguas, Santa Bárbara, la Concordia, Egipto, Centro Administrativo y Catedral, y tiene una población de 23.615 habitantes permanentes (Bogotá cómo vamos, 2014). El centro histórico de Bogotá es declarado patrimonio bajo la categoría de monumento histórico nacional ${ }^{4}$. Esta denominación y su desarrollo operativo le confieren un valor a las viviendas que forman parte de este lugar, adquiriendo la categoría de bienes de interés cultural (BIC). Existe un total de 2.364 predios, de los cuales 54 están declarados como bienes de interés cultural del orden nacional (antiguos monumentos nacionales) y 1.608 son predios de conservación arquitectónica. Esta condición le permite a las instituciones públicas que gestionan este patrimonio establecer acciones de intervención para su conservación y manejo y regular las relaciones entre los habitantes y sus viviendas.

Actualmente, los referentes de la política pública en torno al patrimonio en Colombia insisten en el compromiso que debe asumir el Estado en cuanto a la apropiación social del patrimonio como un eje central ${ }^{5}$. Estos referentes, en contraste con los resultados discutidos en este artículo, indican la pertinencia de desarrollar un análisis crítico de las formas de planeación y gestión participativa del patrimonio en el Distrito Capital ${ }^{6}$. Esto implica revisar la gestión local del patrimonio a través de sus organizaciones gubernamentales y no gubernamentales y la participación ciudadana mediante sus organizaciones civiles cuya acción está vinculada con este aspecto del territorio.

En este sentido, me interesa subrayar en este artículo aquellos resultados que hacen referencia a las formas de coparticipación de las organizaciones gubernamentales y no gubernamentales en torno a la gestión del patrimonio cultural y natural de la ciudad y su territorio, al igual que las afiliaciones ciudadanas que emergen de su gestión en el caso del centro histórico y los humedales ${ }^{7}$.

Para exponer estos dos casos, primero se describen algunos aspectos conceptuales y metodológicos sobre el patrimonio natural y cultural en la ciudad. Particularmente, se exponen las nociones de participación social y la gestión a partir de las redes de práctica que lo producen y mantienen. Así mismo se presentan las preguntas y los métodos utilizados para la recolección de la información, sistematización y análisis. En segundo lugar, se expone el contexto de los lugares y los actores que participan en los procesos de valoración y gestión de éstos como lugares-patrimonio. Igualmente, se presentan algunos resultados de investigación que desvelan las dinámicas de los actores que participan en su gestión, tanto en el centro histórico como en los humedales entre 2000 y 2010. 
Estas dinámicas se reconocen mediante un enfoque relacional, principalmente aplicando el análisis de redes sociales (ARS) (WASSERMAN; FAUST, 1994), camino teórico y metodológico que permite evidenciar los vínculos entre actores, los subgrupos y su centralidad (FREEMAN, 2002) en la gestión de estos valores patrimoniales de la ciudad. Se evidencian y representan mediante grafos $^{8}$ con el programa UCINET (BORGATTI, EVERETT; FREEMAN, 2002) las redes de práctica y sus topologías en torno al patrimonio cultural y natural de la ciudad. Por último, se hacen anotaciones a manera de conclusión sobre la participación en la planeación y la gestión del patrimonio en Bogotá y sobre el enfoque y la interpretación de los datos como un camino de investigación y gestión participativa para los lugares-patrimonio.

\section{LOS LUGARES-PATRIMONIO Y SU GESTIÓN: UNA APROXIMACIÓN RELACIONAL Y DIALÓGICA}

Una de las formas de reconocer el compromiso del Estado y las apropiaciones sociales en torno al patrimonio consiste en el reconocimiento de la existencia de redes de práctica alrededor de un asunto o problema. Éstas están compuestas por las comunidades de práctica, que son redes personales interactuando en el marco de una organización' (TEIGLAND; WASKO, 2005). Las redes de práctica se pueden sostener como tales a partir de la salud de sus vínculos internos y externos (fortaleza, frecuencia, calidad, continuidad). La fortaleza de los vínculos internos depende de los conocimientos, acuerdos y formas de intercambio establecidas en los núcleos de actores de estas redes. Estos núcleos o centros de interacción interorganizacional se constituyen a partir de la capacidad de las redes de práctica; es decir, a partir de la fortaleza de los vínculos entre actores, la que se construye mediante sus intercambios discursivos y de coparticipación en prácticas sociales concretas (KREBS; HOLLEY, 2002).

El reconocimiento de las redes de práctica en relación con el patrimonio de la ciudad se cumplió a través de varios estudios realizados en tres tiempos distintos (2003, 2005 y 2010), a partir de preguntas que intentan dar cuenta de las dinámicas sociales que valoran y gestionan el patrimonio cultural y natural en la ciudad. Estas preguntas son: ¿en qué medida la cuestión patrimonial moviliza a la población de habitantes del centro histórico y de los humedales de Bogotá y a qué segmentos de ella?; ¿en qué medida conocer las formas de apropiación y acción sobre el patrimonio del centro histórico y los humedales por parte de los actores organizados aporta a la gestión del mismo?

Para llegar a los resultados aquí expuestos, se abordó el problema desde diversas fuentes. Primero se hizo una aproximación a las dinámicas de las organizaciones civiles o ciudadanas en torno al patrimonio natural recién
Son representaciones gráficas de las relaciones entre actores, mediante nodos (figuras geométricas) y líneas (con flecha o no debido a si hay direccionamiento o no) organizados de acuerdo a su existencia, cercanía y fortaleza (donde el tamaño de los nodos y el grosor de las líneas muestra estas diferencias) (BORGATTI; EVERETT; FREEMAN, 2002)

9

Una organización, según Agarwal y Gibson, puede ser definida como un arreglo social y socio-ambiental; es decir, un conjunto de reglas y normas formales e informales que conforman las interacciones de los seres humanos con su entorno social, cultural y natural (WIENS, 2005). Las interacciones sociales y socio-ambientales, afirma Leach, regularizan su intercambio en patrones de conducta entre individuos y grupos de la sociedad y su entorno; entonces se puede decir que existe una institución (WIENS, 2005). 
declarado en el POT de Bogotá del año 2000, estudiando 14 organizaciones que actuaron en 16 humedales del Distrito Capital entre 2000 y 2003. Segundo, se analizaron los resultados de la encuesta a 361 hogares del centro histórico y 142 del entorno habitado del humedal Córdoba (PARIAS DURÁN; PALACIO TAMAYO, 2006). También se hizo una entrevista semiestructurada a 18 organizaciones locales que tuvieran relación con el patrimonio cultural en el centro histórico en la década 2000-2010.

\section{El lugar-red: una aproximación a las redes de práctica de los lugares- patrimonio}

En este estudio tenemos dos tipos de lugares-patrimonio: los humedales de Bogotá y el centro histórico. Estos dos lugares son definidos, recordados, vividos, percibidos y construidos por sus residentes y las instituciones que los planifican y desarrollan de muchas maneras distintas, muchas veces no conciliadas. Con el propósito tanto de analizar como de proponer procesos de fortalecimiento de las redes de práctica en torno a la consolidación de estos lugares como lugares patrimonio, recurro a la noción de lugar-red como la unidad de análisis de este estudio (PALACIO, 2003; PALACIO; HURTADO; GARAVITO, 2003). El lugar-red permite ver el lugar como una consecuencia de múltiples discursos, subjetividades, interacciones y relaciones de poder, que se desarrollan en el tiempo y en el espacio, y la red como un patrón de vínculos específicos entre un conjunto determinado de actores, donde cualquier variación en la existencia o en el nivel de fortaleza de un vínculo es significativo y tiene consecuencias sobre el todo. La red está configurada por los nodos o actores y sus vínculos con otros actores o con entidades no humanas a las que el actor se afilia (individual o colectivamente) mediante su práctica, para llevar a cabo sus propósitos. Los vínculos entre los actores pueden ser directos o indirectos; directos cuando los actores están relacionados por una interacción explícita y hay interdependencia; indirectos, cuando los actores están compartiendo una actividad o recurso común (DIANI, 2003: 7).

\section{La planeación y la gestión participativa del patrimonio}

Para abordar la planeación y gestión participativa del patrimonio es preciso establecer qué se entiende por estos conceptos. El patrimonio puede definirse de muchas maneras; su significado originario proviene del latín patrimonüum, que quiere decir "bienes que se poseen gracias a los padres". Esta noción se articula con una regla social, que se vincula a su vez con el derecho natural o las llamadas las leyes de parentesco en el marco de un sistema patriarcal que designa la forma como la riqueza trasciende de generación en generación por vía paterna. Desde esta perspectiva, se construye un sentido de apropiación a partir de unos bienes que incluyen muchas veces las tierras como bien primordial. 
Una visión dinámica y viva de la cultura ha llevado a construir una noción más amplia del patrimonio, que integra la noción de los elementos inmateriales, tales como las prácticas, los saberes y los valores estéticos de los actores que son intricadamente parte de esos territorios y sociedades, cuyas características se incorporan estructuralmente a los primeros (materiales), dándoles contenido y funciones cultural y social, diferenciadas de acuerdo con la época y para colectivos diferentes. Adicionalmente, en la lengua española se aceptan otras acepciones del concepto de patrimonio, que tienen qué ver con las deudas y las obligaciones ${ }^{10}$.

De esta manera, en el marco de la construcción del sentido de pertenencia a la ciudad y la apropiación social de su patrimonio construido y natural, surgen preguntas sobre cómo sus habitantes y sus organizaciones públicas, civiles y privadas construyen su patrimonio históricamente. Es decir lo que unas generaciones dejan a otras en forma de ganancia acumulada de bienes patrimoniales y también sobre las deudas y obligaciones que se adquieren por las acciones pasadas y presentes de dichas generaciones debido a sus usos inadecuados, dejando unas deudas ecológicas y culturales.

En segundo lugar se desarrolla la noción de planeación participativa. Velásquez Carrillo y González (2003) afirman que la planeación participativa es a la vez proceso y escenario. Proceso, porque plantea un conjunto de actividades e interacciones sociales y políticas en torno a la definición de prioridades y a la formulación de caminos para abordarlas. Escenario, porque en estas dinámicas hay lugares de encuentro de voces heterogéneas, tanto por su origen como por sus intereses, que buscan interactuar para dialogar y negociar sus visiones y perspectivas sobre los problemas conjuntos.

En tercer lugar, tenemos la gestión como elemento activo de la planeación. En tanto que tal, la gestión está relacionada con lo creativo, con la acción, con las prácticas que se llevan a cabo para dar cumplimiento a esa planeación; es decir, es la puesta en marcha del ordenamiento de las cosas de acuerdo con la visión que ofrece la planeación. La gestión participativa como proceso de ordenamiento implica la articulación de cuatro elementos: la pertenencia, como un proceso de ensamblaje social que se va construyendo bajo el progresivo establecimiento de vínculos; la diferencia, que es parte de la construcción de los procesos, en tanto cada miembro entra con sus trayectorias y proyectos; la estabilidad, que para este enfoque es relativa, en tanto no busca un punto ideal sino que se va construyendo permanentemente; el deber ser, como producto de una construcción conjunta y permanente entre los miembros y no como una definición a priori (LEE; STENNER, 1999).

En cuarto y último lugar, la participación se define aquí más allá de los medios de representación y de los mecanismos formales que tienen los ciu-
Véase la entrada "patrimonio" en el Diccionario de la lengua española. Real Academia Española. 22. ${ }^{a}$ edición. Madrid: EspasaCalpe, 2001, t. 2. 
Decreto 619 de 2000, por el cual se adopta el Plan de Ordenamiento Territorial para Santa Fe de Bogotá, Distrito Capital, y sus respectivas reformas de 2003, 2004 y 2013 dadanos de involucrarse en los procesos de formulación, realización, evaluación y seguimiento de la acción gubernamental. La participación es en sí misma un proceso mediante el cual los sujetos sociales hacen parte de una acción con otros en el marco de las relaciones de poder. Esta participación reconoce que estas acciones están inmersas en estructuras político-jurídicas pero actúan en ámbitos que las trascienden, es decir, que van más allá de estos límites y son diversos en su naturaleza (ejemplos: movimientos sociales por el agua, redes de ambientalistas, alianzas interorganizativas locales, nacionales y globales, movimientos identitarios).

Los otros, "con quien se es parte de...", puede ser definido como otro igual o diferente de acuerdo con su condición de género, edad, clase, etnia, ideología, pero también de acuerdo con su condición de ser humano o no humano. En este orden de ideas, la participación es un proceso estructurante en el plano social y también en el plano ecológico-ambiental. Es el caso de los humedales y del centro histórico de Bogotá, que son sistemas vivos y de objetos culturales, respectivamente. Ambos son parte del entramado urbano de la ciudad, reconocidos a partir de la acción ciudadana e institucional y su valoración patrimonial formalizada en las normas de ordenamiento de la ciudad $^{11}$.

En síntesis, la planeación y la gestión participativa se definen en esta propuesta como prácticas referidas al ejercicio del poder en un contexto dialógico, que buscan debatir y negociar asuntos del interés de los actores en escenarios de diálogo, con el fin de definir y llevar a cabo sus objetivos y propósitos. Estos objetivos y propósitos, que a su vez tienen relación con la vida de quienes participan, privilegian la existencia de unas formas de relación sobre otras, lo que hace que se mantengan estructuras o redes de práctica dominantes que se la superponen a otras y, en conjunto, dan origen a formas paisajísticas específicas.

\section{LOS HUMEDALES Y EL CENTRO HISTÓRICO EN BOGOTÁ}

En esta sección se presentan el caso de los humedales y el centro histórico de Bogotá como ejemplos de la gestión del patrimonio y sus redes de práctica. Se destaca aquí la emergencia del vínculo de los vecinos de los humedales y la forma en la que se desarrolla la gestión del patrimonio en el centro histórico, con el fin de mostrar dos formas de participación opuestas. Una, movida por el interés de los habitantes urbanos vecinos de los humedales debido a la expansión de la ciudad; otra, caracterizada por la dificultad de interesar al residente del centro histórico, debido a su heterogeneidad, a la movilidad de sus habitantes originarios hacia otras partes de la ciudad y a la relación crítica que tiene el habitante del centro con las instituciones que promueven la conservación del centro histórico como monumento nacional. 


\section{Origen del vínculo entre los humedales y sus vecinos y sus redes de práctica}

Con el crecimiento acelerado de la ciudad, los humedales de Bogotá han experimentado una transformación sin precedentes durante los últimos sesenta años, dando lugar a un fenómeno de extinción y deterioro de uno de los hábitats más representativos de la sabana. Según van der Hammen (2003) a mediados del siglo XX había 50.000 ha de humedales en la sabana de Bogotá, de las cuales solo se mantienen aproximadamente 800 ha dentro del perímetro del Distrito Capital. Este deterioro y extinción acelerada hacen que se pierdan también las funciones ecológicas y culturales, dando origen a la formación de un significado muy negativo por parte de la ciudadanía sobre estos pantanos. Es así como los humedales en las últimas décadas se convierten en sinónimo de "botadero", "cloaca maloliente" y potencial relleno para la urbanización. De esta manera, los humedales llegan a un punto tal que ya no son potencialidad para desarrollo de una cultura sino una amenaza para la salud pública y fuente de riesgo.

A pesar del mal augurio que muestra el panorama de los humedales de Bogotá, esta historia no sigue el lineal rumbo de la muerte y la extinción total e irreversible. En la década de los 80 del siglo XX muchos vecinos urbanos 0 habitantes de pueblos colindantes o en proceso de conurbación con Bogotá -como es el caso de Funza, Soacha y Fontibón- empiezan a observar cambios en los ya conocidos charcos, pantanos o chucuas o a tropezarse con ellos como vecinos que estrenan sus nuevas viviendas en el occidente de la ciudad. Es así como emerge una conciencia ciudadana de tipo ecológico que, en lugar de seguir negando este hábitat insigne de la sabana, se percata de su presencia y quiere hacer algo al respecto. La movilización de estos habitantes se inicia con acciones de defensa y protección ambiental; pasa por actos administrativos y normas que incorporan estos lugares en el sistema de áreas protegidas de la ciudad; y culmina con la formulación de la Política de Humedales del Distrito Capital (2006), marco de las actuales intervenciones de protección y restauración.

Es visible ya en textos y narraciones registradas en estudios anteriores (MOLINA; URIBE; OSORIO, 1996; GALINDO, 2003; PALACIO, 2003; PALACIO, 2006) como surge una relación entre los humedales y sus vecinos. Esta relación se caracteriza por el compromiso de los vecinos con la conservación de los humedales a partir de una sensibilidad, un conocimiento ecológico y una posición ética y política ambiental. Si bien los vínculos que se construyen tienen distintos motivos y fuentes, estos vecinos tienen la particularidad de hacerse responsables directos de su defensa y esta defensa hace énfasis en las características naturales de los ecosistemas, definiéndolos como sistemas vivos donde habitan muchas especies vegetales y animales que consideran valiosas y por las cuales vale la pena luchar. Este compro-

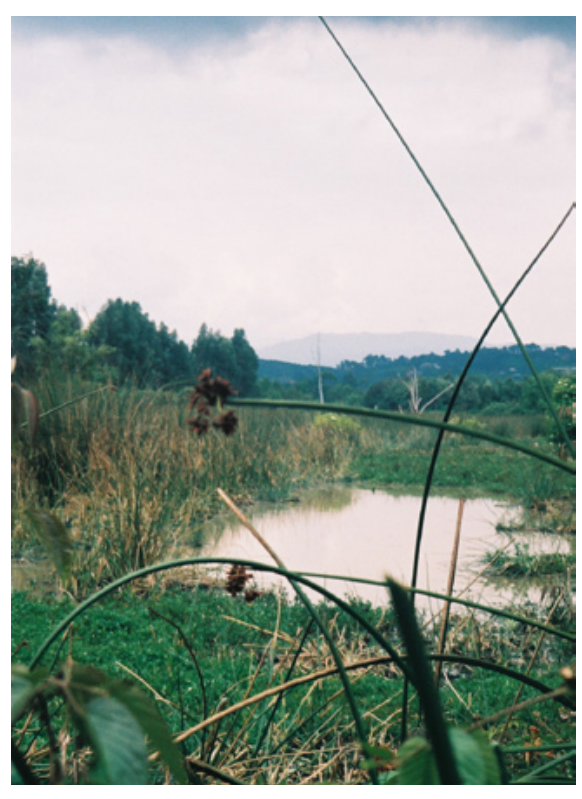

Humedal La Conejera | fuente PALACIO, 2003 

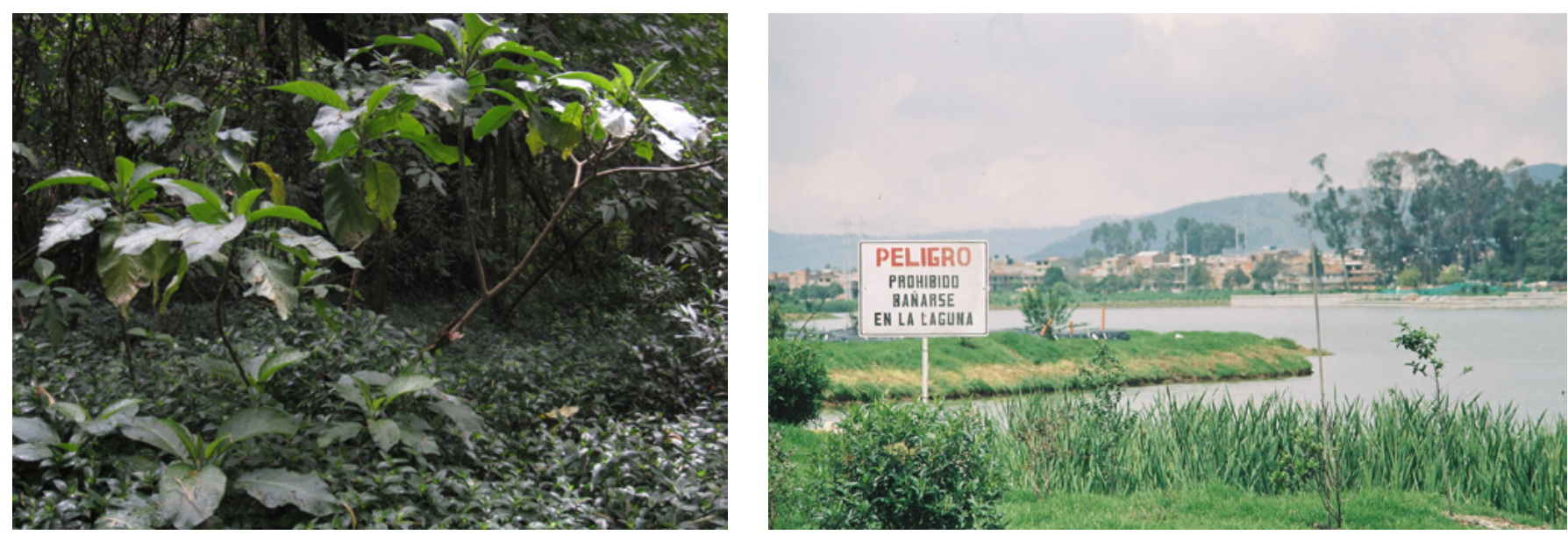

Humedal Córdoba (izquierda) Humedal Juan Amarillo (derecha) | fotos Dolly Cristina Palacio T. miso surge del vecino del humedal que quiere participar directamente en la toma de decisiones sobre su entorno inmediato y actuar usando su conocimiento y sus derechos ciudadanos individuales y colectivos para lograrlo.

Esta iniciativa se consolida primero mediante la formación de grupos y organizaciones locales no gubernamentales que actúan para lograr propósitos afines a la defensa de los humedales en la ciudad o en las zonas de interfase entre Bogotá y otros municipios de la sabana (acciones de denuncia, limpieza, restauración, educación ambiental, entre otras). Posteriormente se fortalece el proceso con la formación de una red de organizaciones, la Red de Humedales de Bogotá y la Sabana (RHBS), que se integra mediante un programa de intercambio y aprendizaje convenido entre los miembros de los grupos vinculados a la defensa de estos humedales en Bogotá. Esta nueva forma de organización y de participación sobrepasa las formas tradicionales de participación política y ciudadana en Bogotá caracterizada muy bien por Gutiérrez (1998).

Este estilo de participación denota una apropiación y un arraigo al lugar donde se vive -en este caso la ciudad-, que se manifiesta con la acción y la toma de una posición ética y política frente a los fragmentos de humedal que estas personas quieren defender. Este estilo de participación vive y representa la ciudad en su dimensión ecológica y ambiental, lo que hace que los habitantes se repiensen como ciudadanos con una formas de verse y de ver el mundo local desde una perspectiva ecológica y ambiental, que se incorporan a su proyecto de vida. A diferencia de muchos movimientos que se fundan en las reivindicaciones sociales o económicas que duran tanto como se consiguen sus logros (obtener la infraestructura de servicios públicos, la vivienda, el empleo) (VELÁSQUEZ CARRILLO; GONZÁLEZ, 2003), esta organización se conecta con un aspecto mucho más fundamental de la calidad de vida y es el derecho a un medio ambiente sano para todos, hoy y en el futuro. Esta noción de "ambiente sano" involucra el cuidado de los 
"sistemas vivos". Una vez adquirida la conciencia sobre la continuidad que requiere el cuidado de "un sistema vivo" se establece un compromiso vital, es decir, no es un compromiso que finalmente obtiene un logro, sino que se construye permanentemente mientras estemos aquí en co-existencia con el planeta.

La experiencia de la Fundación Humedal La Conejera, guiada por Germán Galindo, es reconocida como un ejemplo y modelo a seguir por muchos de los grupos que hoy hacen parte de la RHBS; al igual que experiencias como las de Jorge Zamudio (humedal Capellanía), Lucrecia Sandoval y Helena Torres (humedal Santa María del Lago), Gustavo Alvarado (humedal Juan Amarillo), Marucio Castaño (humedal Córdoba), Humberto Medellín y Consuelo Pérez (humedal Neuta), Pablo Moreno y Iveth Nieves (humedal Tibanica), entre otros muchos, han sido piedra angular del movimiento ciudadano. Con el fin de profundizar en el conocimiento de la formación de esta dinámica conservacionista en la ciudad, a continuación se presenta una síntesis de los tipos de vínculo de los miembros de la RHBS a partir de sus testimonios ${ }^{12}$. Sus visiones sobre los humedales muestran una sensibilidad en el tema ambiental y en particular sobre la conservación de especies y sus hábitats. Esta sensibilidad, sin embargo, parece tener distintas fuentes, observándose tres tipos de origen en los vínculos entre los humedales y sus vecinos.

El primero tipo de vínculo tiene origen en una reminiscencia de un entorno familiar que hace referencia a su infancia, vinculada a una experiencia rural que recuerda el contacto directo con los entornos naturales. El segundo tipo de vínculo se refiere a un acercamiento desde su trayectoria de formación disciplinar y profesional. Es una sensibilidad construida a partir de la experiencia formativa en profesiones o disciplinas como la agronomía y biología que están relacionadas con campos de práctica que los acercan de manera directa a estos hábitats, para cumplir en principio con sus tareas universitarias o profesionales. Estas tareas combinadas con su experiencia de vecinos de humedales en calidad de habitantes de los nuevos barrios de la frontera occidental de Bogotá (desde los barrios de noroccidente como Suba Compartir hasta Castilla al occidente) hacen que sus experiencias cotidianas generen una apropiación de lugar y les haga reflexionar sobre los humedales y los asuman como una causa importante para la ciudad.

El último tipo de vínculo tiene que ver con la sensibilidad hacia el tema social y su relación con los proyectos urbanos que integran el tema ambiental. Este tema se vincula de manera especial al de los derechos humanos y a los de la naturaleza, donde se inscriben personas formadas en ciencias sociales y afines como el derecho y la pedagogía. Estos vecinos ven en estos lugares sitios especiales para el desarrollo humano urbano mucho más cerca de la naturaleza, al igual que ve en estos ambientes naturales hábitats que requieren apoyo para sobrevivir y, por lo tanto, hacen educación ambiental y apli-
12

Grupo focal realizado con 32 miembros de la RHBS en 2002. 
Tabla 1. Centralidades de grado nodal (CGN) de salida (CGNS) y de entrada (CGNE) y centralidad de intermediación $(\mathrm{Cl})$ para los vínculos directos y los indirectos entre actores de la RHBS

| fuente PALACIO; HURTADO, 2005 can las disposiciones constitucionales y legales del derecho colectivo que defienden los derechos a un "ambiente sano" y la protección y conservación de la biodiversidad.

En cuanto a la topología de las interacciones entre las 14 organizaciones civiles que hacen gestión de los humedales en Bogotá podemos evidenciar que la centralidad de la red en ambos casos, interna y externa, está dominada por la Fundación La Conejera y la Junta de Acción Comunal (JAC) Niza, defensores del humedal La Conejera y Córdoba respectivamente. Este papel se ratifica estudiando la posición y cercanía jerárquica de los actores según su participación en subgrupos.

Los vínculos entre actores del entorno o aquellos que son movilizados por la RHBS se definen según los pares de actores que tienen vínculos directos con actores de la RHBS. Los vínculos directos entre actores de la RHBS y de su entorno corresponden a ejecución, financiación, litigios o facilitación de acciones y proyectos, entre otros. Se identificaron 43 actores del entorno ${ }^{13}$.

A partir de considerar medidas de centralidad -grado e intermediación- y de cohesión de subgrupos (WASSERMAN; FAUST, 1994), se encuentra de manera consistente que los actores más prominentes son la RHBS misma, el Ministerio del Medio Ambiente, la Empresa de Acueducto y Alcantarillado de Bogotá (EAAB), el Departamento Administrativo del Medio Ambiente del Bogotá (DAMA), los colegios vecinos, la autoridad ambiental regional (CAR), las JAC y las Alcaldías Locales.

\begin{tabular}{|c|c|c|c|c|c|c|}
\hline \multirow[t]{2}{*}{ Organización } & \multirow[t]{2}{*}{ Abreviación } & \multicolumn{3}{|c|}{ Vínculos directos } & \multicolumn{2}{|c|}{ Vínculos indirectos } \\
\hline & & CGNS & CGNE & $\mathrm{Cl}$ & CGN & $\mathrm{Cl}$ \\
\hline Fundación Humedales La Conejera & F. La Conejera & 12 & 12 & 38 & 87 & 17 \\
\hline Junta de Acción Comunal Niza & JAC Niza & 12 & 10 & 22 & 83 & 17 \\
\hline Centro Mixto Conserv. Amb. & CMCA & 9 & 4 & 5 & 63 & 1 \\
\hline Corpomilenio & Corpomilenio & 4 & 4 & 1 & 61 & 1 \\
\hline AUNAR & AUNAR & 5 & 6 & 0 & 63 & 3 \\
\hline La Tibanika Fundación Ambiental & TIBANIKA & 3 & 6 & 0 & 52 & 1 \\
\hline ADESA & ADESA & 8 & 7 & 7 & 47 & 0 \\
\hline Fundación Torca-Guymaral & FTG & 4 & 5 & 2 & 49 & 0 \\
\hline Fundación Humedales El Tintal & F. El Tintal & 6 & 8 & 2 & 57 & 0 \\
\hline ASINUS & ASINUS & 3 & 7 & 8 & 53 & 0 \\
\hline Fundación La Tingua & F. La Tingua & 7 & 6 & 8 & 37 & 0 \\
\hline AMVIDA (en formalización) & AMVIDA & 1 & 2 & 0 & 58 & 1 \\
\hline CORGUALI & CORGUALI & 9 & 3 & 2 & 55 & 0 \\
\hline Cabildo Verde de Soacha & CVS & 4 & 7 & 4 & 39 & 0 \\
\hline
\end{tabular}




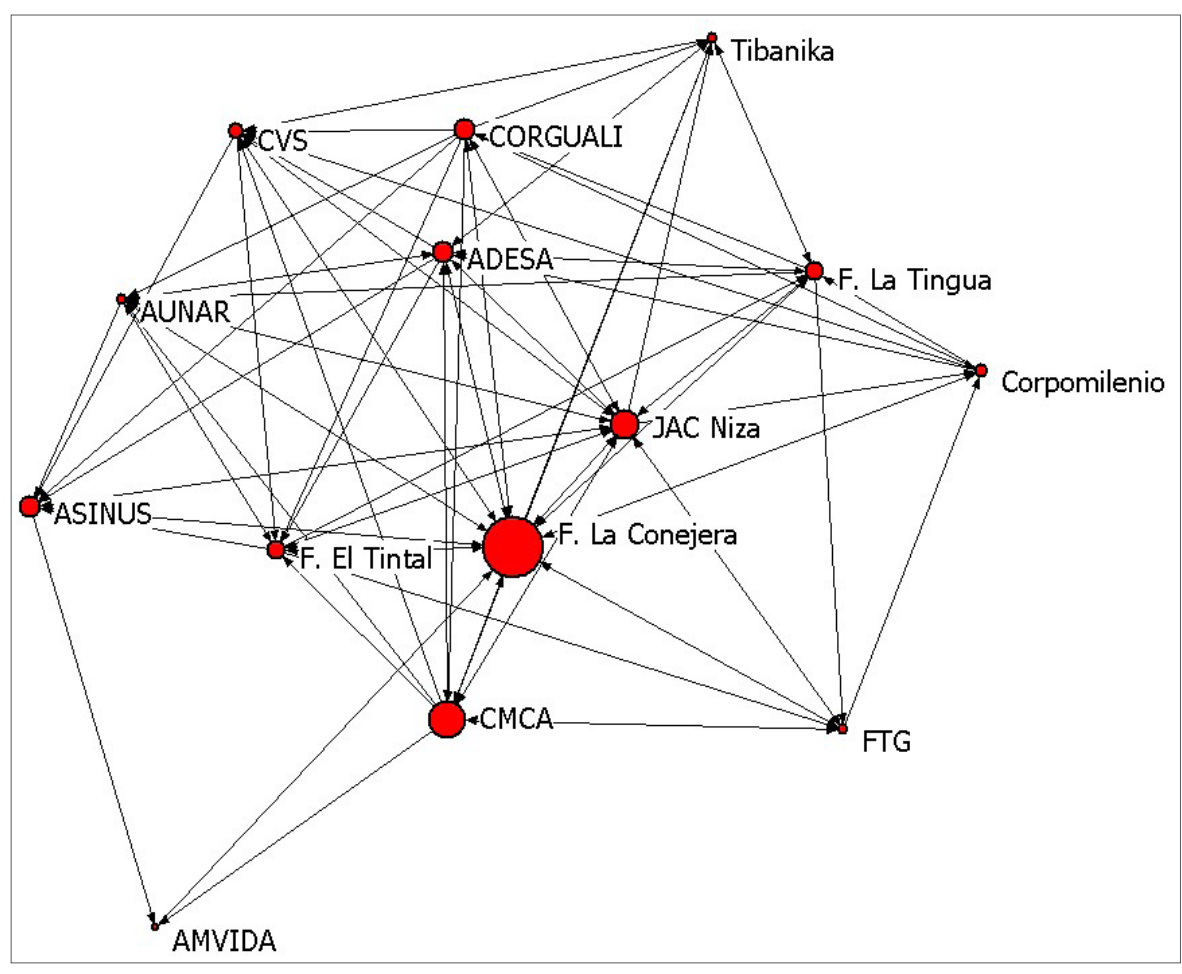

Gráfico 1. Red de actores de la RHBS según sus vínculos directos entre actores de acuerdo a su coparticipación en proyectos de gestión de los humedales. El tamaño de los nodos representa el grado de intermediación I fuente PALACIO; HURTADO, 2005

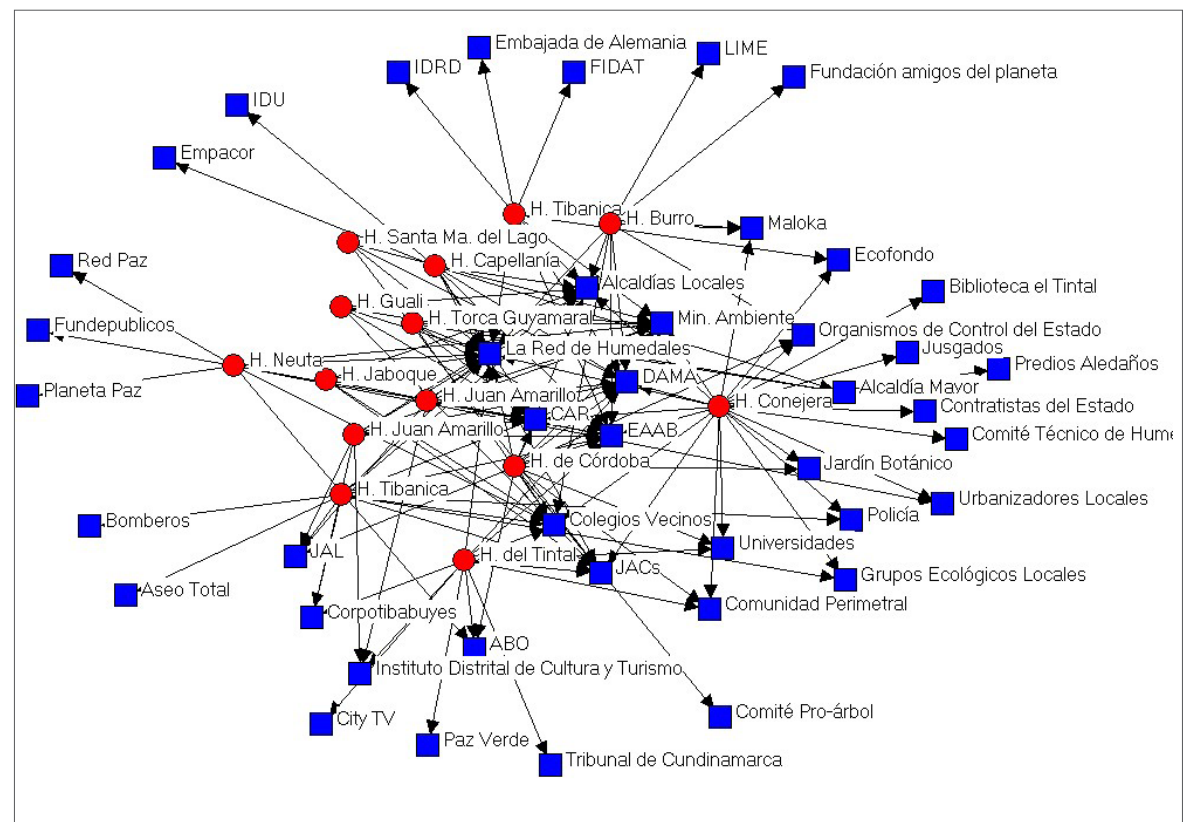

Gráfico 2. Debajo, emergencia de la red de gestión ambiental de los actores del entorno de la RHBS. Círculos rojos: nodos de la RHBS, cuadrados azules: actores del entorno | fuente PALACIO; HURTADO, 2005
13

Ministerio del Medio Ambiente, Alcaldía Mayor, Empresa de Acueducto y Alcantarillado de Bogotá (EAAB), Corporación Autónoma Regional (CAR), la Red de Humedales de la Sabana de Bogotá (RHBS), colegios vecinos, Departamento Administrativo del Medio Ambiente (DAMA), Tribunal de Cundinamarca, Comunidad Perimetral, Juntas de Acción Comunal (JAC), alcaldías locales, Aseo Total, LIME (empresa de aseo), policía, bomberos, grupos ecológicos locales, urbanizadores locales, Asociación Ornitológica de Bogotá (ABO), Planeta Paz, Red Paz, Fundepúblicos, Ecofondo, Comité Técnico de Humedales de Bogotá (CTHB), predios aledaños, universidades, contratistas del Estado, juzgados, Paz Verde, City TV, Jardín Botánico, Comité Pro-árbol, organismos de control del Estado, juntas administradoras locales (JAL), Corpotibabuyes, Instituto Distrital de Cultura y Turismo (IDCT), Fundación Amigos del Planeta, Biblioteca El Tintal, Maloka, Embajada de Alemania, Fundación para el Desarrollo y Medio Ambiente del río Tunjuelito (FIDAT), Instituto Distrital de Recreación y Deporte (IDRD), Instituto de Desarrollo Urbano del Distrito (IDU), Empacor. 


\begin{tabular}{|c|c|c|c|c|}
\hline Nombre o razón social & Naturaleza jurídica & Ámbito & Constitución & Temática \\
\hline $\begin{array}{l}\text { Instituto Distrital de Patrimonio } \\
\text { Cultural }\end{array}$ & Pública & Distrital & 2006 & $\begin{array}{l}\text { Conservación y restauración } \\
\text { patrimonial }\end{array}$ \\
\hline $\begin{array}{l}\text { Gestora de cultura-Secretaria de } \\
\text { Cultura }\end{array}$ & Pública & Local & 2005 & Promotor cultural \\
\hline Alcaldía Local & Pública & Local & 1993 & Gobierno local \\
\hline \multirow{2}{*}{$\begin{array}{l}\text { Consejo de Arte, Cultura y } \\
\text { Patrimonio }\end{array}$} & \multirow{2}{*}{$\begin{array}{l}\text { Espacio de } \\
\text { participación } \\
\text { formal }\end{array}$} & \multirow{2}{*}{ Local } & 2005 & \multirow{2}{*}{$\begin{array}{l}\text { Definición proyectos culturales en } \\
\text { plan de desarrollo local }\end{array}$} \\
\hline & & & 2008 reforma & \\
\hline Junta de Acción Local & Pública & Local & 1992 & Desarrollo local \\
\hline Consejo de Planeación Local-CPL & $\begin{array}{l}\text { Instancia de } \\
\text { participación } \\
\text { formal }\end{array}$ & Local & 2000 & Planeación local \\
\hline JAC Concordia & ESAL-Solidaria & Barrial & 1962 & \multirow{4}{*}{ Desarrollo de la comunidad } \\
\hline JAC Egipto & ESAL-Solidaria & Barrial & 1967 & \\
\hline JAC Santa Bárbara & ESAL-Solidaria & Barrial & 2004 & \\
\hline JAC Belén & ESAL-Solidaria & Barrial & 1969 & \\
\hline Club La Candelaria & $\begin{array}{l}\text { Privada con } \\
\text { animo de lucro }\end{array}$ & Local & 2005 & Turismo patrimonial \\
\hline $\begin{array}{l}\text { Fundación para la Conservación y la } \\
\text { Restauración del Patrimonio Cultural }\end{array}$ & Privada-ESAL & $\begin{array}{l}\text { Nacional, } \\
\text { distrital y } \\
\text { local }\end{array}$ & 1998 & $\begin{array}{l}\text { Conservación y restauración } \\
\text { patrimonial }\end{array}$ \\
\hline Corporación Cultural La Gestoría & Privada-ESAL & Distrital & 2002 & Gestión cultural \\
\hline $\begin{array}{l}\text { Recorridos históricos y fotos } \\
\text { antiguas }\end{array}$ & $\begin{array}{l}\text { Privada-informal } \\
\text { virtual }\end{array}$ & Distrital & 2007 & Patrimonio histórico \\
\hline Asocandelaria & Privada-ESAL & Local & 2007 & Asociación de dueños de bares \\
\hline Candelaria Internacional & Privado-formal & Local & $\begin{array}{l}\text { En proceso } \\
\text { constitución }\end{array}$ & Patrimonio cultura y turismo \\
\hline $\begin{array}{l}\text { Fundación Jóvenes Construyendo } \\
\text { Alternativa Social-JOCOALSO }\end{array}$ & Privado-ESAL & Local & 2006 & $\begin{array}{l}\text { Jóvenes por los derechos } \\
\text { humanos en las comunidades }\end{array}$ \\
\hline $\begin{array}{l}\text { Comité Cívico por Amor a La } \\
\text { Candelaria }\end{array}$ & Privado-ESAL & Local & 1993 & Promotora social y cultural \\
\hline
\end{tabular}

Tabla 2. Organizaciones asociadas a temas patrimoniales en la Candelaria | fuente PALACIO, 2011 


\section{Las redes de práctica del patrimonio en el centro histórico}

El centro histórico de Bogotá, como la gran mayoría de otros centros históricos en Europa y Latinoamérica, ha sido una estrategia que surge de la preocupación de las élites al ver que se podían borrar las huellas de la historia a partir de las grandes transformaciones urbanas que se dieron con la industrialización y la modernización. Dicha preocupación dio origen a un proceso de declaratoria de monumentos nacionales relacionados con los inmuebles de la ciudad para mantenerla accesible a otras vivencias en el tiempo, como parte de la identidad y sentido de pertenencia de una sociedad (VAN DER HAMMEN; LULLE; SIERRA et ál., 2011). Este proceso de patrimonialización se hizo en un principio bajo políticas que buscaban consolidar proyectos hegemónicos, a partir de la idea de constituir una memoria colectiva que valore elementos particulares de la historia, la cultura y la estética propias de los grupos en el poder (GARCÍA CANCLINI, 1997; TELLO, 2002).

En Bogotá, bajo este mismo postulado, se define una zona como centro histórico en $1963^{14}$ buscando conservar su arquitectura de manera integral. En esta declaratoria se incluyen una serie de edificaciones muy variadas, construidas en distintas épocas, transformadas a través del tiempo e intervenidas para responder a las necesidades y las posibilidades de sus dueños a lo largo del tiempo, dando muestra de una hibridación en estilos, usos y grados de deterioro en que se encuentran las edificaciones. Se busca, mediante este proceso de patrimonialización, detener el deterioro de la zona y contribuir a su recuperación (VAN DER HAMMEN; LULLE; SIERRA et ál., 2011).

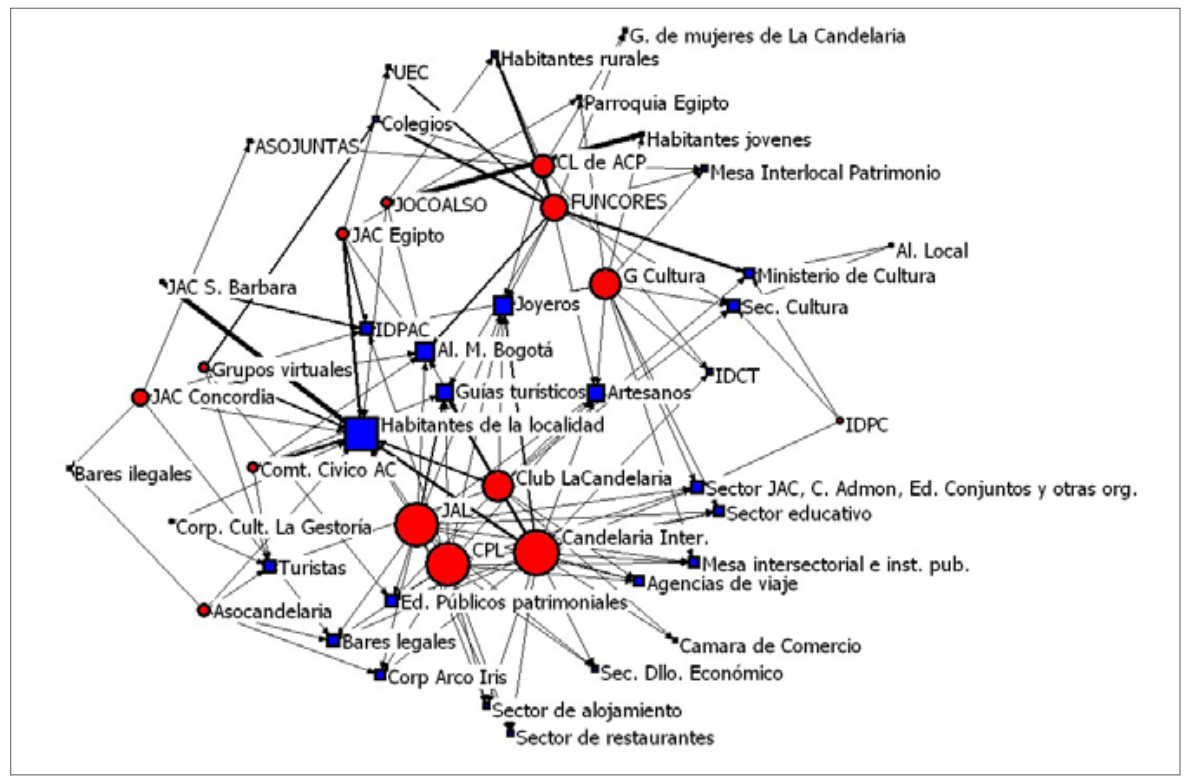

\section{4}

Decreto 264/1963 que declara el centro histórico de Bogotá monumento nacional, a lo que hay que añadir el Decreto 678/1994 y la Ley 397/1997 que establece que "los bienes declarados monumentos nacionales con anterioridad a la presente ley, así como los bienes integrantes del patrimonio arqueológico serán considerados como bienes de interés cultural".
Gráfico 3. Actores organizados del patrimonio del centro histórico y su entorno: entrevistados (rojo) $\mathrm{y}$ actores que participan en sus acciones (azul). Tamaño del nodo por centralidad de grado, es decir, según número de lazos con otros actores a partir de la coparticipación en acciones. Grosor de la línea por fortaleza del vínculo, dada por la cantidad de acciones en las que coparticipa cada par de actores en acciones conjuntas | fuente PALACIO, 2011 


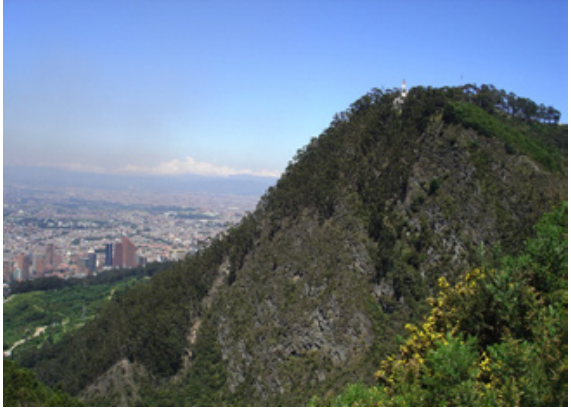

El centro histórico visto desde los cerros orientales | fuente PALACIO, 2011

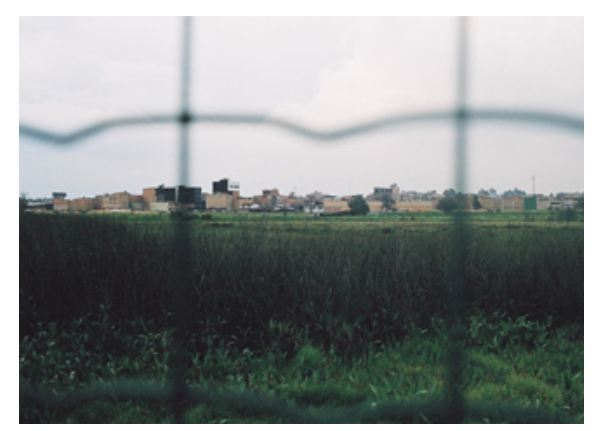

Humedal del Burro

| foto Dolly Cristina Palacio T

A pesar de los esfuerzos normativos arriba expuestos, la conformación de redes de práctica y la participación social en la gestión del patrimonio es un tema que emerge recientemente, en la agenda de la ciudad. Esta emergencia temática no presenta desarrollos sino hasta el último período, entre el 2005 y el 2010, debido a que se crean espacios nuevos de participación en el tema de cultura, a partir del de la creación del Sistema Distrital de Arte, Cultura y Patrimonio y los Consejos Locales de Arte, Cultura y Patrimonio (Consejos de ACP), como escenarios de participación que se reglamentan y se hacen operativos desde el 2005 (decretos 221 de 2002 y 627 de 2007). Pero este escenario, como lo veremos más adelante, muestra un desarrollo sectorial separado de la acción local, lo que confirma lo que Velásquez (2009) dice sobre la política pública de participación en Bogotá, al argumentar que cada uno de los escenarios de participación han sido creados sin "punto de amarre" que permita su articulación y la coordinación de su acción entre los sectores y los territorios.

En 2006 (PARIAS; PALACIO) con una encuesta a 361 habitantes del centro histórico se establece que sólo 9 de ellos manifiestan alguna afiliación a organizaciones locales, ninguna de ellas con fines de protección al patrimonio, hecho significativo en un lugar que es declarado monumento histórico con 1.608 predios de conservación. Con la profundización que se hace en 2009-2011, se puede decir que sigue siendo muy incipiente el desarrollo de una ciudadanía activa y participante en la gestión del patrimonio, así como existe una debilidad en la articulación de las organizaciones locales en la gestión del territorio local en el caso del centro histórico de Bogotá.

A partir de las encuestas de 2006 y las entrevistas a los habitantes en 2010, no se encuentran mayores pistas sobre organizaciones locales orientadas a hacer gestión del patrimonio del centro histórico. Por lo tanto, se hizo un rastreo de las organizaciones a partir de ir a escenarios de participación (discusión sobre el Plan Zonal del Centro (PZC), reuniones del clúster de turismo, etc.) o a partir de visitas a negocios, donde se pudieron establecer afiliaciones a escenarios de negociación más colectiva. Es así como se encontraron 
18 organizaciones locales que tenían algún vínculo con el patrimonio (ver tabla 2), bien sea por su misión o por las acciones que desarrollan en relación con el uso comercial, el uso turístico o la conservación del patrimonio. Sin embargo, muchas de ellas no tienen relación o misiones directas con lo que aquí llamamos patrimonio.

En el gráfico 3 (ver p. 91) se puede ver cómo las organizaciones establecen vínculos entre ellas a partir de las acciones que cada una lleva a cabo. Se observan en este grafo tres tipos de dinámica. Una se articula en torno a procesos de participación y formulación de proyectos sobre el patrimonio cultural directamente. Este conjunto está alrededor del Consejo de Arte, Cultura y Patrimonio (CL de ACP), FUNCORES y la Gestora de Cultura (G. Cultura), quienes movilizan procesos de definición de proyectos de patrimonio cultural tanto para su inclusión en el Plan de Desarrollo Local como para actividades propias.

El otro conjunto o subgrupo está relacionado con la actividad del llamado Clúster de Turismo, gestado y promovido por algunos ediles de la JAL, los que, en el Consejo de Participación Local, han propuesto proyectos que involucren económicamente a la población local aprovechando la condición de centro histórico de la localidad. El tercer subgrupo, es el trabajo comunitario directo, que, aunque más precario, muestra una dinámica en la que coparticipan las JAC y distintas poblaciones de la comunidad de residentes o habitantes de la localidad. Se destacan como actores centrales para la primera dinámica, la Gestora de Cultura y FUNCORES; para el segundo, Candelaria Internacional, la JAL y el CPL; y para el tercero, las JAC Concordia, JAC Egipto y JOCOALSO.

En el gráfico también se evidencia la fortaleza del vínculo entre los actores a partir de la coparticipación en varias actividades, lo que permite ver la construcción de vínculos propiamente dichos. Igualmente, observamos la importancia de los actores en cuanto a mediadores o puentes que articulan otros actores al convocarlos en actividades comunes. Se destacan FUNCORES para el primer conjunto; Candelaria Internacional para el segundo; y JAC Concordia para el tercero.

\section{PUNTOS PARA EL ANÁLISIS CRÍTICO DE LA PLANEACIÓN Y GESTIÓN PARTICIPATIVA DEL PATRIMONIO}

En el desarrollo de las investigaciones en cuestión se reconocen diferencias en la dinámica de la participación en la planeación y gestión del patrimonio. En particular, se observa un doble comportamiento de la ciudadanía y sus organizaciones civiles. Por un lado, para los humedales esta dinámica derivó en la declaratoria de estos lugares como patrimonio ambiental y natural de la 


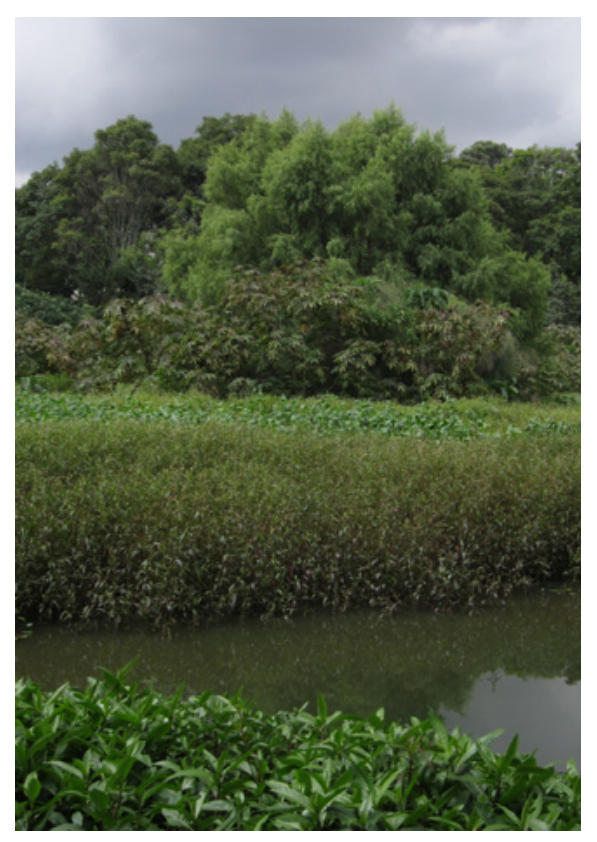

Humedal Córdoba | fotos Dolly Cristina Palacio T.

15

Decretos 619 de POT 2000 y sus respectivas reformas de 2003,2004 y 2013.
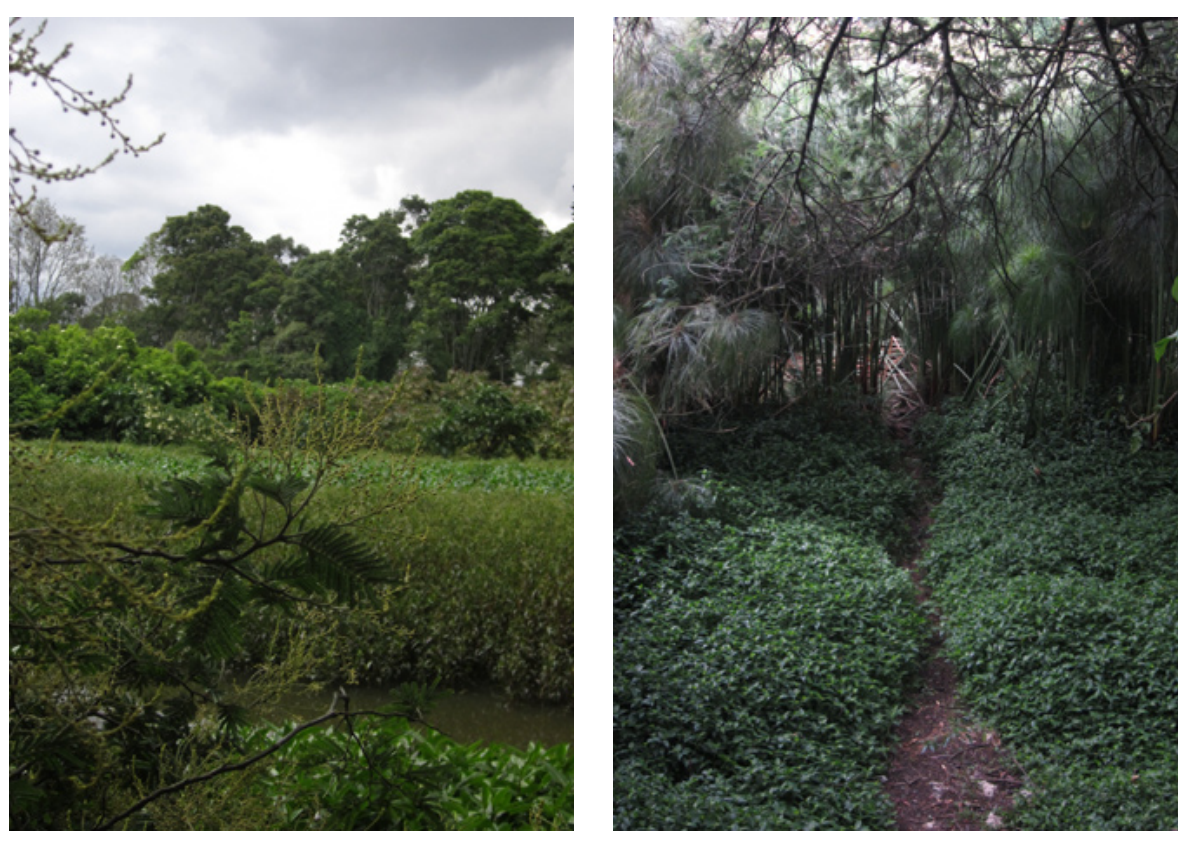

ciudad bajo la categoría de parques ecológicos distritales ${ }^{15}$. En el centro histórico, por el contrario, está dinámica muestra un conjunto de organizaciones que se articulan a los programa de las instituciones gubernamentales, pero no tienen una misión específica en torno a la conservación del centro histórico como un valor patrimonial de la ciudad.

La participación social para las organizaciones civiles que defienden los humedales de la ciudad, está relacionada con su sentido de pertenencia al lugar y de su activismo como parte de un proyecto de vida. Esto los involucra de manera integral como seres humanos en un entorno natural y cultural. Por otra parte, para el centro histórico se ha evidenciado que falta desarrollo organizacional, articulación y cooperación interorganizacional, así como la inexistencia de una cultura ciudadana en torno a éste como patrimonio cultural. Así mismo, se detecta una falta de articulación de la gestión del patrimonio material con el patrimonio intangible en el centro histórico de la ciudad.

Esto ha influido en la falta de acompañamiento y veeduría de la gestión del patrimonio de uso residencial por parte de los ciudadanos-habitantes ante los gobiernos locales y las instituciones competentes. En el caso contrario, se da la gestión ambiental en los humedales altamente acompañados de una gestión directa de las organizaciones civiles, quienes han desarrollado mecanismos complejos y especializados de veeduría. Adicionalmente, se observa una incipiente inclusión de valores patrimoniales construidos por las propias prácticas y valoraciones locales en el centro histórico y una alta especialización y desarrollo de conocimiento para el caso de la gestión de 

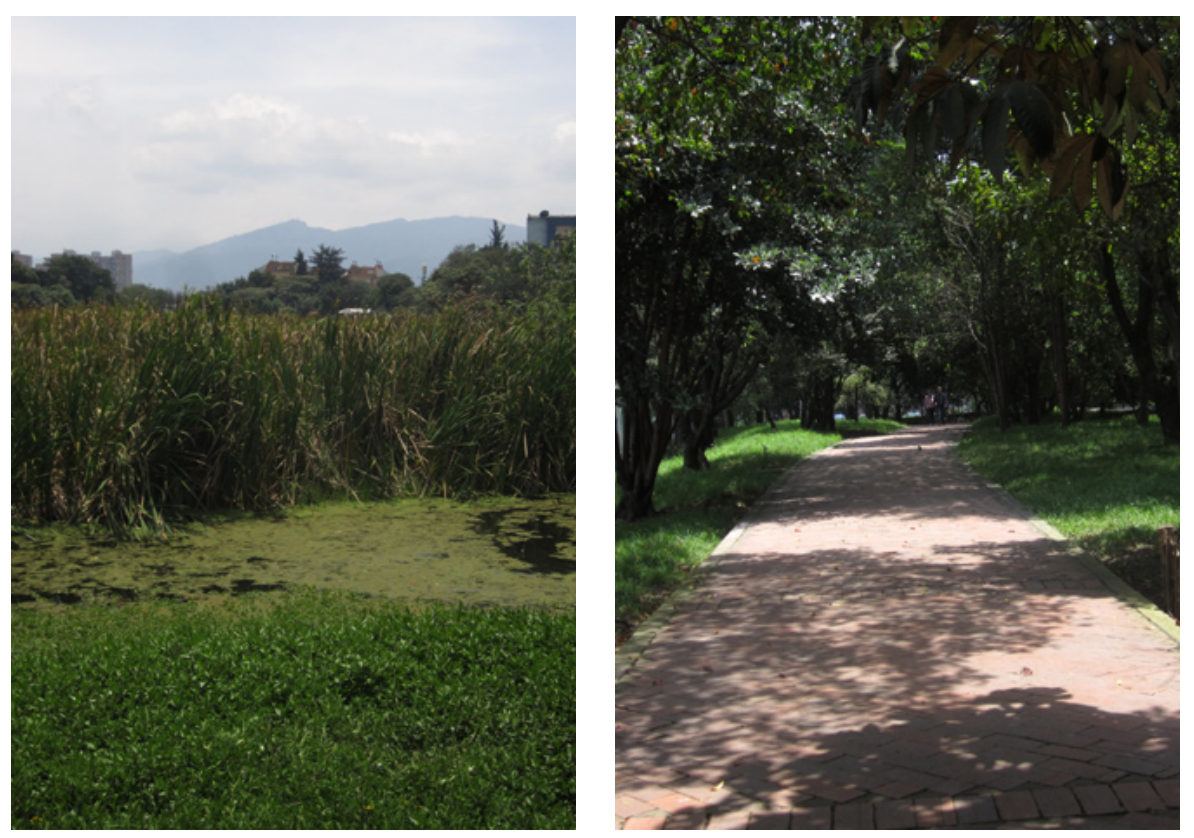

los humedales. Esto nos impulsa a plantear la necesidad de señalar la importancia de pensar qué impulsa a los ciudadanos a participar, qué emerge aquí como sentido de apropiación y por qué en un caso y no en el otro hay una movilización tan fuerte.

Finalmente, la gestión en red y la participación ciudadana organizada aparecen como dos retos para asumir en el marco de la planeación y gestión participativa del patrimonio en la ciudad, donde uno de los nichos para cumplir estos retos parece estar en las propuestas de alianza respecto a temas como el hábitat, cuyo eje puede estar definido por los bienes patrimoniales naturales y culturales de la ciudad y las prácticas que los sostienen ${ }^{16}$. Si consideramos que las prácticas sociales aún no están armonizadas al $100 \%$ con las propuestas oficiales (VAN DER HAMMEN; PALACIO, 2006), podemos concluir que aún es necesario abrir canales de diálogo en el marco de los instrumentos de planificación ya existentes, que no son pocos, para generar nuevos consensos y reconocer tanto la valoración social como técnica del patrimonio en escenarios conjuntos de toma de decisiones.

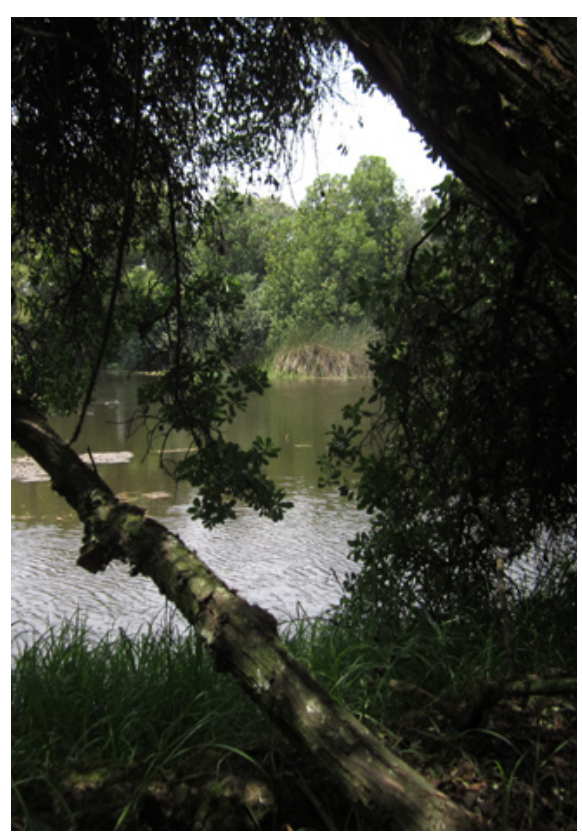

Humedal de Santa María del Lago | fotos Dolly Cristina Palacio T., 2014

16

Véase Bogotá Cómo Vamos, un programa de control ciudadano que evalúa los cambios de la calidad de vida en la ciudad a través de indicadores técnicos y de percepción <http:// www.bogotacomovamos.org/> [consulta: 28/ 02/2014] 
- BORGATTI, S. P.; EVERETT, M. G.; FREEMAN, L. C. (2002) Ucinet for Windows: Software for Social Network Analysis. Harvard Analytic Technologies. Harvard, MA: Analytic Technologies, 2002

- CALlON, M. (1986) Some Elements Of Sociology Of Translation. Domestication Of The Scallops And The Fishermen Of St. Brieuc Ba". En LOW, J.(ed.) Power, Action And Belief: A New Sociology Of Knowledge? London: Routledge \& Kegan Paul, 1986, pp. 197-233

- La POLÍTICA de humedales del Distrito Capital. Bogotá: Alcaldía Mayor, Departamento Administrativo del Medio Ambiente, 2006, 120 p. <http://ambientebogota.gov.co/c/ document_library/get_file?uuid=b3186a1c-c2a6-4cae-8e853eaecfee4fb7\&groupld=55886> [consulta: 05/02/2014]

- HISTORIA de los humedales de Bogotá. Con énfasis en cinco de ellos. Bogotá, DC: [DAMA.], 2000. 107 p.

- DIANI, M. (2003) Introduction. En DIANI, M.; MCADAM, D. (ed) Social Movements and Networks. Relational Approaches to Collective Action. New York: Oxford University Press, 2003, pp. 1-18

- FREEMAN, L. C. (2002) Detectando grupos sociales en datos cuantitativos. En GIL MENDIETA, J.; SCHMIDT, S. Análisis de Redes: aplicaciones en Ciencias Sociales. Ciudad de México: Instituto de Investigaciones en Matemáticas Aplicadas; Sistemas Universidad Nacional Autónoma de México, 2002, pp. 23-37

- GALINDO, G. (2003) Experiencia colectiva en la recuperación del Humedal La Conejera. En Los Humedales de Bogotá y la Sabana. sl: Acueducto de Bogotá, 2003, vol. 1, pp. $217-228$

- GARCíA CANCLINI, N. (1997) Imaginarios urbanos. Buenos Aires: Editorial Universitaria de Buenos Aires, 1997

- GutiÉRREZ, F. (1998) La Ciudad Representada. Política y conflicto en Bogotá. Bogotá: TM Editores-IEPRI, 1998

- hammen, VAN DER. T. (2003) Los Humedales de la Sabana: origen, evolución, degradación y restauración. En Los Humedales de Bogotá y la Sabana. sl: Acueducto de Bogotá, 2003, pp. 19-52

- KREBS, V; HOLLEY. J (2002) Building Smart communities thought network weaving <http://www.orgnet. com/BuildingNetworks.pdf> [consulta 28-02-2014]

- LATOUR, B. (1999) On Recalling Ant. En LAW, J.; HASSARD, J. (ed.) Actor-Network Theory And After. Oxford: Blackwell, 1999, pp. 15-25

- LAW, J. (1999) Notes On The Theory Of The ActorNetwork: Ordering, Strategy And Heterogeneity. En LAW, J.; HASSARD, J. (ed.) Actor-Network Theory And After. Oxford: Blackwell, 1999
- LAW, J.; URRY, J. (2004) Enacting the Social. Economy and Society, vol. 33, part 3, 2004, pp. 390-410

- LEACH, M. (1994) Rainforest Relations. Gender and Resource Use among the Mende of Gola, Sierra Leone. Edinburgh: Edinburgh University Press for the International African Institute, London, 1994

- LEE, N.; STENNER, P. (1999) Who pays? Can we pay them back? En LAW, J.; HASSARD, J. (ed.) Actor-Network Theory And After. Oxford: Blackwell, 1999, pp. 90-112

- MOLINA, F.; URIBE, E.; OSORIO, J. (1996) Gente, Ciudad y Medio Ambiente. Bogotá: DAMA, 1996

- PALACIO, D. (2011) Ciudadanías, territorio e hibridación del patrimonio. El caso del patrimonio de uso residencial en el Centro Histórico de Bogotá. En LULLE, T.; URBINA, A. DE (ed.) Vivir en el centro histórico de Bogotá: Patrimonio construido y actores Urbanos. Bogotá: ColcienicasUniversidad Externado de Colombia, 2011

- PALACIO, D. (2006) Chucuas Bogotensis y sus vecinos urbanos: emergencia de una conciencia ecológica participativa. En NAIL, S. (ed.) Bosques urbanos en América Latina. Usos, funciones y representaciones. Bogotá: Universidad Externado de Colombia, 2006, pp. 263-304

- PALACIO, D.; HURTADO, R. (2005) Narrativas y redes de la gestión ambiental de los humedales de Bogotá Nómadas (Col), n. ${ }^{\circ} 22$, abril, 2005, pp. 140-150

- PALACIO, D.; PARIAS, A.; GARAVITO, L. et ál. (2005) El enfoque de redes socioambientales. Una propuesta para la identificación y la caracterización de actores vinculados a la gestión de la conservación in situ. En ARANGO, N. (ed.) Bases para el diseño de sistemas regionales de áreas protegidas. Bogotá: Instituto de Investigación de Recursos Biológicos Alexander von Humboldt, 2005, pp. 81-139

- PALACIO, D. (2003) La gestión ambiental en Las Chucuas de Bogotá: Una red socioambiental en tensión. En Los Humedales de Bogotá y la Sabana. sl: Acueducto de Bogotá, 2003, vol. 1, pp. 201-216

- PALACIO, D.; HURTADO, R.; GARAVITO, L. (2003) Redes Socioambientales en tensión: el caso de la gestión ambiental de los humedales de Bogotá. Redes. Revista Hispana para el análisis de redes sociales [en línea], vol. 4, n. ${ }^{\circ}$ 6, junio-julio $2003<$ http://revistes.uab.cat/redes/article/ view/45> [consulta: 06/02/2014]

- PARIAS DURÁN, A.; PALACIO TAMAYO, D. (2006) La Construcción de Lugares- Patrimonio. El Centro Histórico y el Humedal Córdoba en Bogotá. Bogotá: Universidad Externado de Colombia y COLCIENCIAS, 2006

- TEIGLAND, R.; WASKO, M. (2005) Networks of Practice. A Review of Inter-organizational Knowledge Exchange En COAKES, E.; CLARKE, S. (ed.) The Encyclopedia of 
Communities of Practice in Information and Knowledge Management. London: Idea Group Inc, 2005

- TELLO, S. (2002) Introducción patrimonio e interdisciplinariedad. En En torno al patrimonio y la interdisciplinariedad. Lima: Universidad de San Martín de Porres, 2002

- TURNER, B. J. (1997) Spirals, Bridges And Tunnels: Engaging Human-Environment Perspectives. Geography. Ecumene., vol 4, n. ${ }^{\circ} 2,1997$, pp. 196-217

- VAN DER HAMMEN, M. C.; LULLE, T.; SIERRA, G. et ál. (2011) Habitar el patrimonio: Prácticas y representaciones de los habitantes del centro histórico de Bogotá entorno a la vivienda patrimonial. En LULLE, T.; URBINA, A. DE (ed.). Vivir en el centro histórico de Bogotá: Patrimonio construido y actores Urbanos. Bogotá: Colciencias-Universidad Externado de Colombia, 2011

- hammen, M. C.,VAN DER; LULle, T.; PALACiO, D. (2009) La construcción del patrimonio como lugar: Un estudio de caso en Bogotá. Antípoda, n. ${ }^{\circ}$ 9, 2009, pp. 6186

- HAMEN, M. C. VAN DER ; PALACIO, D. (2006) Género y capital cultural en lugares-patrimonio. En La Construcción de Lugares- Patrimonio. El Centro Histórico y el Humedal Córdoba en Bogotá. Bogotá: Universidad Externado de Colombia y COLCIENCIAS, 2006, pp. 265-232

- VELÁSQUEZ CARRILLO, F.; GONZÁLEZ, E. (2003) ¿Qué ha pasado con la participación ciudadana en Colombia? Bogotá: Fundación Corona, 2003

- WASSERMAN, S.; FAUST, K. (1994) Social Network Analysis. Methods and Application. Cambridge: Cambridge University press, 1994 (Structural Analysis in the social sciences; 8)

- WIENS, PH. (2005) The Gendered Nature of Local Institutional Arrangements for Natural Resource Management: A Critical Knowledge Gap for Promoting Equitable and Sustainable NRM in Latin America. Ottawa: International Development Research Centre, 2005 (Rural Poverty and Environment Working Paper Series; 14) $<$ http://www.idrc.ca/uploads/user-S/1122989130114Wiens. pdf> [consulta: 06/02/2014] 